\title{
DESEMULSIFICAÇÃO DE PETRÓLEO UTILIZANDO RADIAÇÃO MICRO-ONDAS MONOMODO
}

\author{
C. M. STRIEDER, G. D. IOP, L.S.F. PEREIRA, M. F. PEDROTTI, M. S. P. ENDERS, \\ L. SCHMIDT, E. I. MULLER e E. M. M. FLORES*

\begin{abstract}
Universidade Federal de Santa Maria, CEP 97015-900, Santa Maria, RS, Brasil.
\end{abstract} \\ *ericommf@gmail.com
}

\begin{abstract}
RESUMO - Tendo em vista a inviabilidade do processamento de petróleos emulsionados com água, juntamente com a necessidade de métodos de desemulsificação eficazes, faz-se necessário o desenvolvimento de metodologias alternativas para a separação de emulsões do tipo A/O. Desta maneira, neste trabalho é proposta a utilização de um reator micro-ondas monomodo, uma vez que este método possui maior taxa de transferência de energia quando comparado com o aquecimento convencionalmente empregado para desemulsificação. O equipamento de MW utilizado possibilita a focalização do feixe de radiação incidente na amostra e a quantificação da energia absorvida e refletida por esta. Amostras com diferentes teores de água foram avaliadas e submetidas ao aquecimento em reator micro-ondas monomodo. Posteriormente, foi feita a adição de desemulsificante à mistura que foi submetida ao banho-maria para a separação das fases. Avaliou-se a eficiência do método proposto, através da visualização do volume de água separado após o procedimento. A velocidade de separação das fases das amostras submetidas às condições otimizadas foi superior à velocidade de separação das emulsões submetidas ao aquecimento convencional, portanto o método proposto apresentou-se adequado para a separação de emulsões do tipo A/O em escala laboratorial.
\end{abstract}

\section{INTRODUÇÃO}

O petróleo é constituído por uma mistura de hidrocarbonetos de ocorrência natural, oriundo da decomposição da matéria orgânica pela ação da temperatura e pressão, sendo depositado ao longo dos anos em rochas que atuam como reservatórios (Behrenbruch e Dedigama, 2007). Durante a exploração do petróleo, à medida que a pressão dos reservatórios diminui a água move-se para o interior dos reservatórios deste. Para que a mistura de água e óleo possa ser processada, esta é transportada em dutos que operam com escoamento turbulento e expõe a mistura à agitação e ao cisalhamento, possibilitando assim a incorporação das gotas de água (fase dispersa) na fase óleo (fase contínua), formando uma emulsão. A quantidade de água incorporada varia de acordo com as características dos reservatórios e com a idade dos poços, sendo que os métodos empregados para o processamento do petróleo também influenciam nos teores de água das emulsões (Djuve et al, 2007).

A formação de emulsões, assim como sua estabilidade depende da composição do petróleo, da presença de surfactantes (emulsificantes naturais) e do tamanho das gotas da fase 


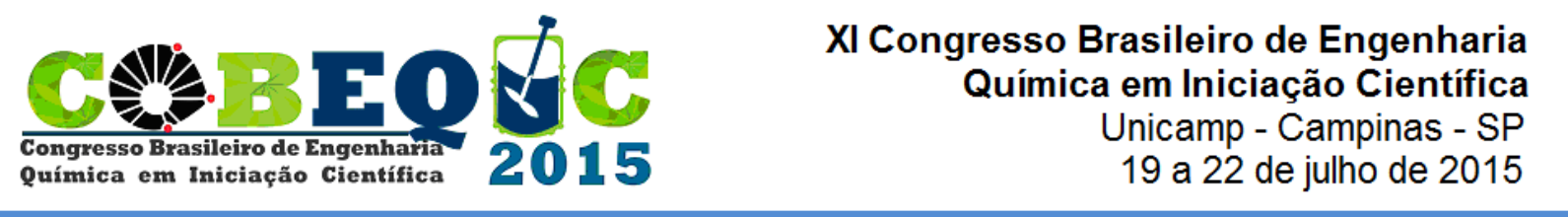

dispersa, sendo que, quão menores as gotas, mais difícil torna-se a separação das fases (Balinov et al., 1994). A água incorporada contém geralmente sais dissolvidos e outros compostos indesejáveis ao petróleo os quais, se não forem removidos durante 0 processamento primário, poderão ocasionar problemas nas unidades de refino, como a corrosão de equipamentos (Speight, 2002). Na presença de água, a viscosidade do petróleo aumenta, tornando o fluido mais resistente ao transporte ao longo das tubulações, ocasionando aumento dos custos de processamento (Bryers, 1996).

A desestabilização de emulsões através do aquecimento e da adição de agentes desemulsificantes é o método convencional empregado para promover a separação das fases. Os desemulsificantes são compostos que interagem com a fase aquosa e também com a fase orgânica, promovendo o deslocamento dos compostos surfactantes diminuindo, assim, a tensão interfacial e causando a coalescência das gotas de água. Entretanto, tendo em vista a necessidade da separação das fases das emulsões formadas de modo mais eficiente durante o processamento do petróleo, vários métodos têm sido desenvolvidos, como o tratamento eletrostático, o uso de membranas filtrantes, a energia US, dentre outros (Pereira, 2012).

Dentre as fontes alternativas de energia, destaca-se ainda a utilização de radiação microondas que tem sido aplicada em diversas áreas. Chan e Chen (2002) atribuem a crescente aplicação da radiação micro-ondas, à rápida transferência de energia, que ocorre em função dos fenômenos de migração iônica e rotação das moléculas. Tendo em vista então, a eficiência da radiação MW para realização do aquecimento das emulsões sintéticas, juntamente da adição de desemulsificante químico no meio, o presente trabalho propõe a avaliação do sistema que emprega um reator micro-ondas monomodo através do estudo de parâmetros operacionais definidos, em função da melhor eficiência e velocidade de separação de emulsões de petróleo.

\section{MATERIAIS E MÉTODOS}

Para avaliação da desemulsificação de petróleos foi utilizado um sistema de microondas monomodo, como apresentado na Figura 1, com gerador de 2,45 GHz (Sairem, Neyron, França), que fornece potência variável de até $2 \mathrm{~kW}$. Este equipamento, o qual foi adaptado no Laboratório de Análises Químicas, Industriais e Ambientais (LAQIA) do departamento de química da UFSM, possibilita a medida da potência de MW absorvida e da refletida pela amostra além de focalizar o feixe de radiação micro-ondas diretamente sobre a mesma.

Figura 1 - Sistema de MW monomodo

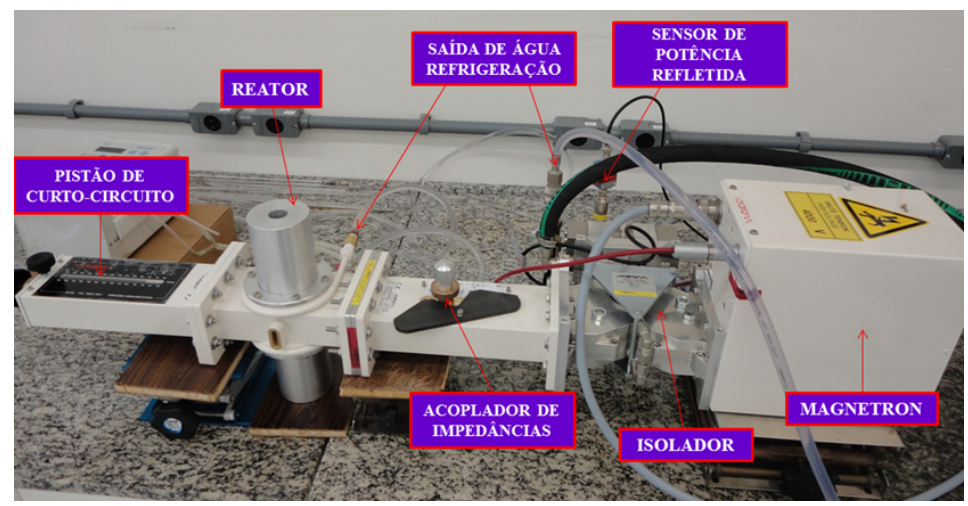


As emulsões sintéticas de petróleo foram preparadas a partir do óleo com ${ }^{\circ}$ API de 19,5 e teor de água menor do que $1 \%$. Neste sentido, foram preparadas emulsões com diferentes teores de água $\left(20\right.$ e $\left.70 \%, \mathrm{~m} \mathrm{~m}^{-1}\right)$, mantendo fixa a concentração da solução salina $\left(250 \mathrm{~g} \mathrm{~L}^{-1}\right.$ de $\mathrm{NaCl})$ e a mediana do diâmetro médio de gotas de até $10 \mu \mathrm{m}$. Foram pesados $80 \mathrm{~g}$ de emulsão em frascos graduados sendo inseridos na cavidade do forno de micro-ondas. Para o programa de aquecimento com MW, a potência foi aplicada até ser atingida a temperatura de 88 e $103{ }^{\circ} \mathrm{C}$ (correspondentes às viscosidades de 16 e $25 \mathrm{cSt}$, respectivamente).

A emulsão sintética de petróleo foi aquecida até que a temperatura desejada fosse atingida e posteriormente, adicionou-se desemulsificante químico (Disssolvan, Clariant) à mesma (concentração de 50 e $100 \mathrm{mg} \mathrm{kg}^{-1}$ ). Em seguida a emulsão foi submetida ao aquecimento em banho-maria durante o tempo de decantação (até $15 \mathrm{~min}$ ). A eficiência do método proposto foi avaliada através da visualização do volume de água separado após a exposição da emulsão ao aquecimento, como é mostrado na Figura 2.

Figura 2 - Visualização do volume de água separado

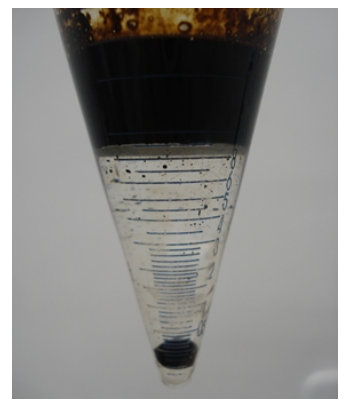

\section{RESULTADOS E DISCUSSÕES}

De acordo com os resultados obtidos, para as emulsões contendo $20 \%$ de água, nas quais foi adicionado $50 \mathrm{mg} \mathrm{kg}^{-1}$ de desemulsificantes não ocorreu a separação das fases para ambas formas de aquecimento (MW e convencional) e temperaturas utilizadas $\left(88^{\circ} \mathrm{C}\right.$ e 103 ${ }^{\circ} \mathrm{C}$ ). Por outro lado, com a adição de $100 \mathrm{mg} \mathrm{kg}^{-1}$ de desemulsificante, a eficiência de separação com uso da radiação MW foi superior quando comparado ao uso do aquecimento convencional, após 15 min de decantação da emulsão (Tabela 1). Além do mais, observou-se que, para a temperatura de $88^{\circ} \mathrm{C}$, a separação das fases iniciou após 9 minutos de decantação, para aquecimento MW.

Tabela 1 - Eficiência de desemulsificação (\%) para emulsão contendo $20 \%$ de água. Ensaios feitos com uso de $100 \mathrm{mg} \mathrm{kg}^{-1}$ de desemulsificante químico em diferentes temperaturas.

\begin{tabular}{ccccc}
\hline \multirow{2}{*}{$\begin{array}{c}\text { Tempo de } \\
\text { decantação (min) }\end{array}$} & \multicolumn{2}{c}{$88^{\circ} \mathrm{C}$} & \multicolumn{2}{c}{$103{ }^{\circ} \mathrm{C}$} \\
\cline { 2 - 5 } & $\begin{array}{c}\text { Aquecimento } \\
\text { convencional }\end{array}$ & $\begin{array}{c}\text { Aquecimento } \\
\text { por MW }\end{array}$ & $\begin{array}{c}\text { Aquecimento } \\
\text { convencional }\end{array}$ & $\begin{array}{c}\text { Aquecimento por } \\
\text { MW }\end{array}$ \\
\hline 3 & 0 & 0 & 0 & 0 \\
9 & 0 & 0 & 5 & 6 \\
15 & 4 & 15 & 10 & 17 \\
\hline
\end{tabular}


Os resultados dos ensaios feitos com emulsões contendo $70 \%$ de água na temperatura de $88{ }^{\circ} \mathrm{C}$ podem ser observados na Tabela 2. De acordo com os resultados obtidos, a eficiência de desemulsificação foi superior (15 e 18\% para o uso de desemulsificante na concentração de $50 \mathrm{mg} \mathrm{kg}^{-1}$ e $100 \mathrm{mg} \mathrm{kg}^{-1}$, respectivamente) com uso da radiação MW em comparação ao aquecimento convencional e 15 min de decantação. Desta forma, resultados satisfatórios foram obtidos uma vez que ocorreu a separação de, aproximadamente $56 \%$ da fase aquosa da emulsão com uso da maior concentração de desemulsificante químico.

Tabela 2 - Eficiência de desemulsificação (\%) para emulsão contendo 70 \% de água. Ensaios feitos com uso de desemulsificante $\left(50\right.$ e $\left.100 \mathrm{mg} \mathrm{kg}^{-1}\right)$ na temperatura de $88{ }^{\circ} \mathrm{C}$.

\begin{tabular}{ccccc}
\hline \multirow{2}{*}{$\begin{array}{c}\text { Tempo de } \\
\text { decantação (min) }\end{array}$} & \multicolumn{2}{c}{$50 \mathrm{mg} \mathrm{kg}^{-1}$} & \multicolumn{2}{c}{$100 \mathrm{mg} \mathrm{kg}^{-1}$} \\
\cline { 2 - 5 } & $\begin{array}{c}\text { Aquecimento } \\
\text { convencional }\end{array}$ & $\begin{array}{c}\text { Aquecimento } \\
\text { por MW }\end{array}$ & $\begin{array}{c}\text { Aquecimento } \\
\text { convencional }\end{array}$ & $\begin{array}{c}\text { Aquecimento } \\
\text { por MW }\end{array}$ \\
\hline 3 & 0 & 0 & 0 & 23 \\
9 & 6 & 26 & 16 & 47 \\
15 & 28 & 43 & 38 & 56 \\
\hline
\end{tabular}

Para os ensaios feitos na temperatura de $103{ }^{\circ} \mathrm{C}$, a eficiência de separação das fases para as emulsões contendo $70 \%$ de água pode ser observada da Tabela 3 . De acordo com os resultados observados, a velocidade inicial de separação da água da emulsão foi superior quando aquecimento por radiação MW foi utilizado. Além do mais, foi possível observar que para a maior concentração de desemulsificante o uso da radiação MW promoveu a separação de, aproximadamente $30 \%$ de água com apenas 3 min de decantação da emulsão. É possível verificar também que após 15 min de decantação, uma eficiência de $65 \%$ foi alcançada quando empregada radiação MW (100 mg kg-1 de desemulsificante). Ambos comportamentos já eram esperados uma vez que o uso da radiação $\mathrm{MW}$, juntamente com a adição de agente desemulsificante, favorece o processo de separação de emulsões de petróleo.

Tabela 3 - Eficiência de desemulsificação (\%) para emulsão contendo 70 \% de água. Ensaios feitos com uso de desemulsificante $\left(50\right.$ e $\left.100 \mathrm{mg} \mathrm{kg}^{-1}\right)$ na temperatura de $103{ }^{\circ} \mathrm{C}$.

\begin{tabular}{ccccc}
\hline \multirow{2}{*}{$\begin{array}{c}\text { Tempo de } \\
\text { decantação (min) }\end{array}$} & \multicolumn{2}{c}{$50 \mathrm{mg} \mathrm{kg}^{-1}$} & \multicolumn{2}{c}{$100 \mathrm{mg} \mathrm{kg}^{-1}$} \\
\cline { 2 - 5 } & $\begin{array}{c}\text { Aquecimento } \\
\text { convencional }\end{array}$ & $\begin{array}{c}\text { Aquecimento } \\
\text { por MW }\end{array}$ & $\begin{array}{c}\text { Aquecimento } \\
\text { convencional }\end{array}$ & $\begin{array}{c}\text { Aquecimento por } \\
\text { MW }\end{array}$ \\
\hline 3 & 0 & 3 & 1 & 28 \\
9 & 15 & 24 & 33 & 51 \\
15 & 36 & 48 & 53 & 65 \\
\hline
\end{tabular}

\section{CONCLUSÕES}

A utilização do aquecimento de emulsões sintética A/O com o uso de um reator microondas monomodo proporcionou, de modo geral, maiores eficiências de desemulsificação e também maior velocidade de separação das fases da emulsão quando comparada ao aquecimento convencional. Além do mais, foi observado que o uso de desemulsificante favoreceu a separação das fases da emulsão, uma vez que quando utilizado em concentrações mais elevadas, a eficiência de desemulsificação foi superior. Desta forma, a radiação MW 


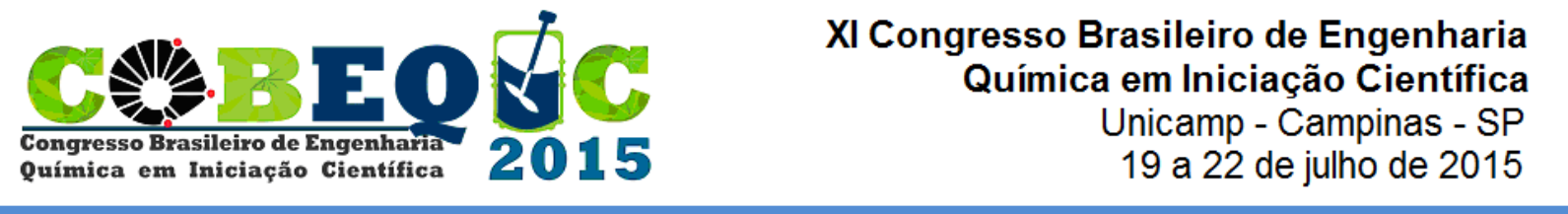

pode ser considerada uma fonte alternativa de aquecimento para promover a desemulsificação de emulsões sintéticas de petróleo, em escala laboratorial. Testes posteriores em planta piloto, assim como análise econômica detalhada do procedimento são necessários para certificar a valia do método em escala industrial.

\section{NOMENCLATURA}

A/O, emulsão do tipo água em óleo

cSt, unidade de viscosidade cinemática centistokes

$\mathrm{GHz}$, unidade de frequência gigahertz

$\mathrm{kW}$, unidade de potência quilowatt

MW, micro-ondas, do inglês microwave

US, ultrassom, do inglês ultrasound

\section{REFERENCIAS}

BALINOV, B., URDAHL, O., SÖDERMAN, O., SJÖBLOM, J., Characterization of waterin-crude oil emulsions by the NMR self-diffusion technique, Colloids and Surfaces A: Physicochemical and Engineering Aspects, v. 82, p. 173-181, 1994.

BEHRENBRUCH, P., DEDIGAMA, T., Classification and characterisation of crude oils based on distillation properties, Journal of Petroleum Science and Engineering, v. 57, p. 166-180, 2007.

CHAN, C. C., CHEN, Y. C., Demulsification of w/o emulsions by microwave radiation, Separation Science and Technology, v. 37, p. 3407-3420, 2002.

DJUVE, J., YANG, X., FJELlANGER, I. J., SJÖBLOM, J., PELIZZETTI, E., Chemical destabilization of crude oil based emulsions and asphaltene stabilized emulsions, Colloid \& Polymer Science, v. 279, p. 232-239, 2001.

PEREIRA, L. S. F. Extração assistida por radiação micro-ondas para a remoção de água, sal e sedimentos de petróleo e posterior caracterização. Dissertação de Mestrado Universidade Federal de Santa Maria, 2012.

SPEIGHT, J. G. Handbook of petroleum product analysis. New Jersey: Editora John Wiley \& Sons, 2002. 